\title{
IMPLEMENTASI REST DAN SISTEM MANAJEMEN PADA VIRTUAL SHOP BERBASIS 3D
}

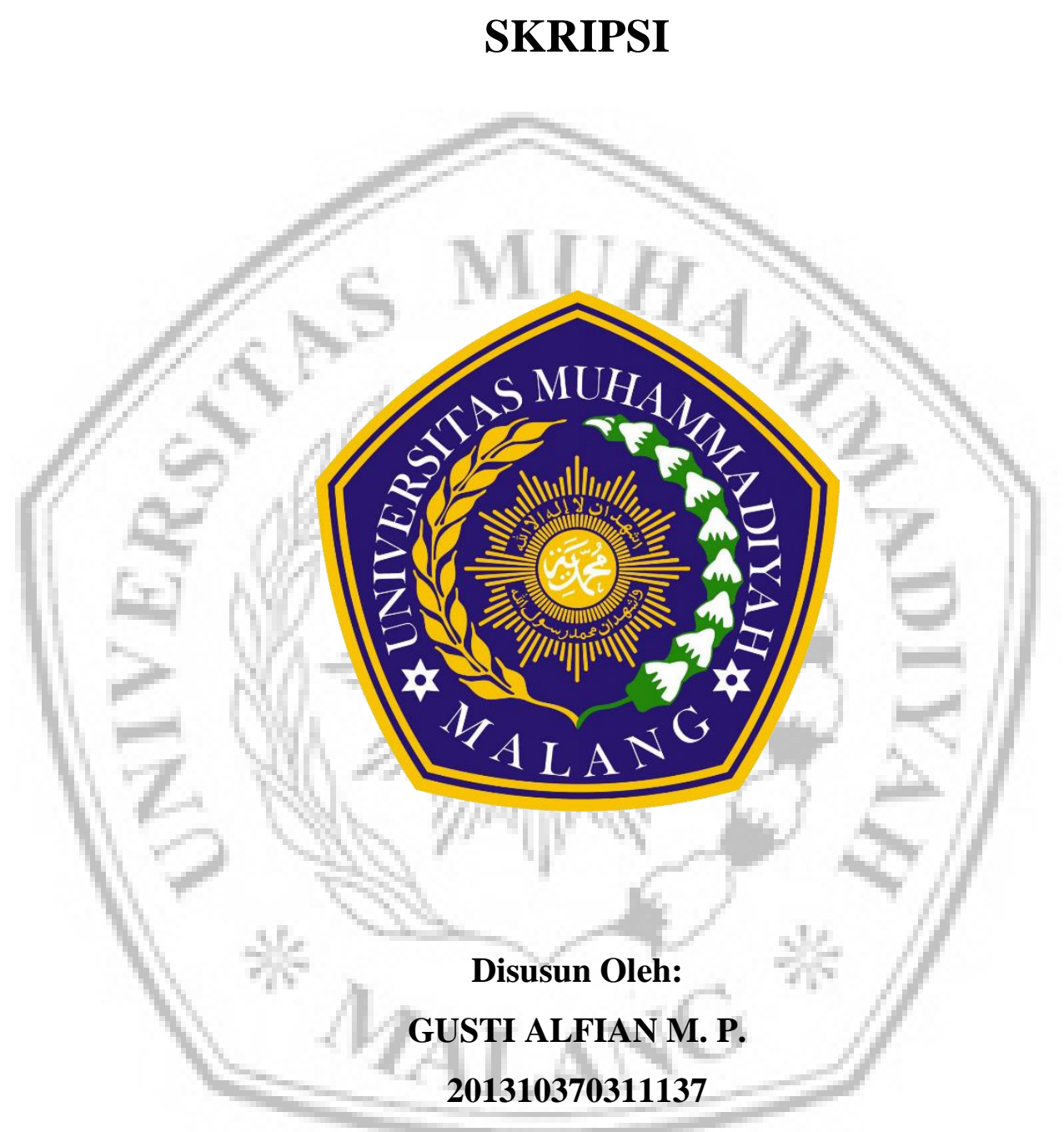

FAKULTAS TEKNIK

JURUSAN TEKNIK INFORMATIKA

UNIVERSITAS MUHAMMADIYAH MALANG

2018 


\section{SURAT PERNYATAAN}

Assalamu'alaikum Wr. Wb.

Yang bertandatangan di bawah ini:

Nama

: Gusti Alfian M. P.

Tempat, Tanggal Lahir

: Sampit, 19 Oktober 1995

NIM : 201310370311137

Fakultas / Jurusan.

: Teknik / Informatika

Menyatakan bahwa karya ilmiah / Tugas Akhir saya yang berjudul

"IMPLEMENTASI REST DAN SISTEM MANAJEMEN PADA VIRTUAL SHOP

\section{BERBASIS 3D"}

Adalah merupakan bukan karya tulis orang lain, baik sebagian maupun keseluruhan, kecuali dalam bentuk kutipan yang kami sebutkan sumbernya.

Demikian surat pernyataan ini dibuat dengan sebenar-benarnya dan apabila pernyataan ini tidak benar, saya bersedia mendapatkan sanksi akademis.

Wassalamu'alaikum Wr. Wb.

Malang, 12 Januari 2018

Yang menyatakan,

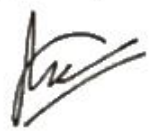

Gusti Alfian M. P.

Mengetahui,

Pembimbing I

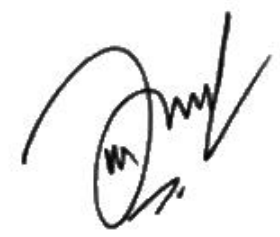

Maskur, S.Kom, M.Kom. NIP. 108.1410.0542
Pembimbing II

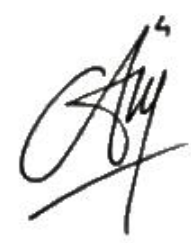

Lailatul Husniah, S.ST, M.T. NIP. 108.1612.0580 


\section{LEMBAR PERSETUJUAN}

\section{IMPLEMENTASI REST DAN SISTEM MANAJEMEN PADA VIRTUAL SHOP BERBASIS 3D}

Disusun oleh :

Gusti Alfian M. P

201310370311137

Telah Memenuhi Persyaratan Guna Meraih Gelar Sarjana Strata 1 Teknik Informatika Universitas Muhammadiyah Malang

Menyetujui,
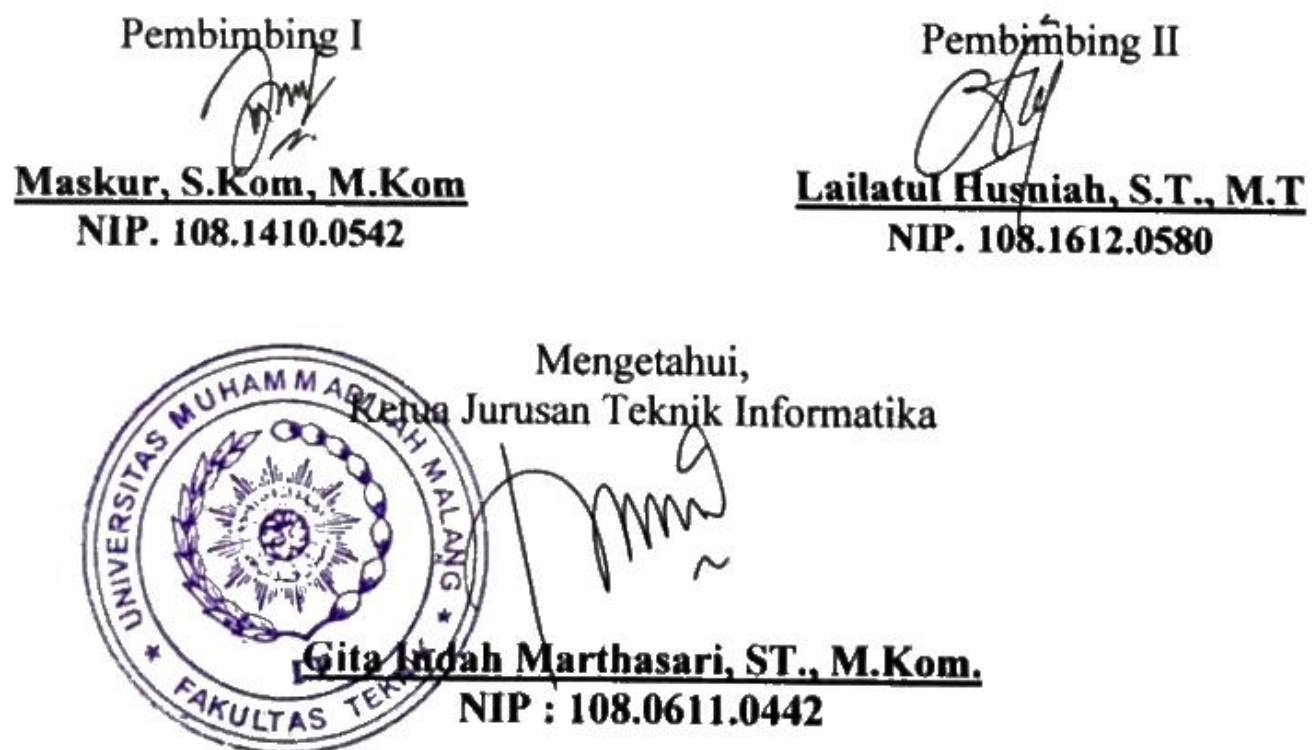


\section{LEMBAR PENGESAHAN}

\section{IMPLEMENTASI REST DAN SISTEM MANAJEMEN PADA VIRTUAL}

SHOP BERBASIS 3D

\section{TUGAS AKHIR}

Sebagai Persyaratan Guna Meraih Gelar Sarjana Strata I Teknik Informatika Universitas Muhammadiyah Malang Disusun Oleh:

\section{GUSTI ALFIAN M. P. 201310370311137}

Tugas Akhir ini telah diuji dan dinyatakan lulus melalui sidang majelis penguji Pada tanggal 22 Januari 2018

\section{Menyetujui}
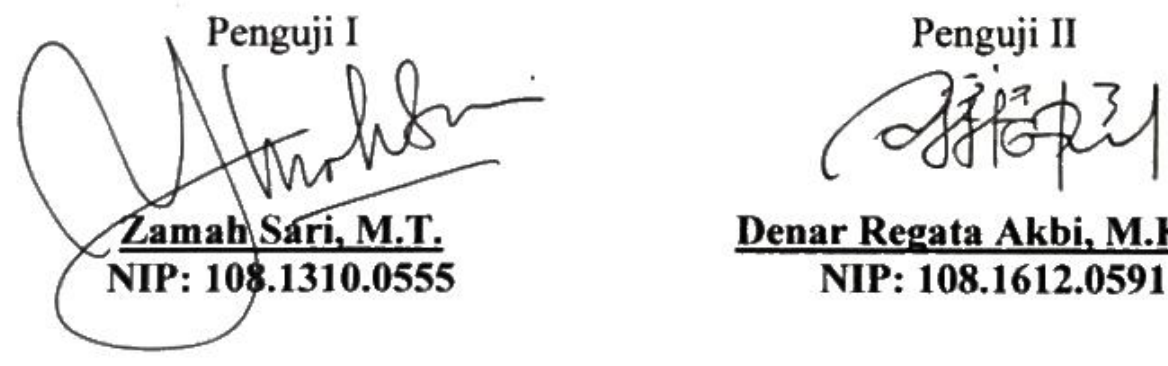

Denar Regata Akbi, M.Kom. NIP: 108.1612.0591 


\section{KATA PENGANTAR}

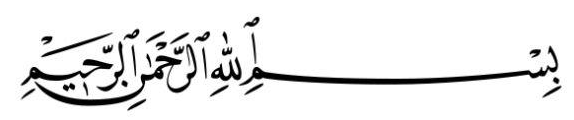

Assalamu'alaikum Warahmatullahi. Wabarakatuh.

Segala puji bagi Allah SWT, yang telah memberikan Rahmat dan Karunianya, sehingga penulis dapat menyelesaikan skripsi yang berjudul:

\section{"Implementasi REST dan Sistem Manajemen pada Virtual Shop"}

Skripsi ini merupakan salah satu syarat studi yang harus ditempuh oleh seluruh mahasiswa Universitas Muhammadiyah Malang, guna menyelesaikan akhir studi pada jenjang program Strata 1.

Peneliti menyadari masih banyak kekurangan dan keterbatasan dalam penulisan tugas akhir ini. Untuk itu, penulis sangat mengharapkan saran yang membangun agar tulisan ini dapat berguna untuk perkembangan ilmu pengetahuan kedepan.

Wassalamu'alaikum Warahmatullahi Wabarakatuh.

Malang, 6 Januari 2018

Gusti Alfian M. P 


\section{DAFTAR ISI}

HALAMAN JUDUL

LEMBAR PERSETUJUAN .................................................................. $\mathrm{i}$

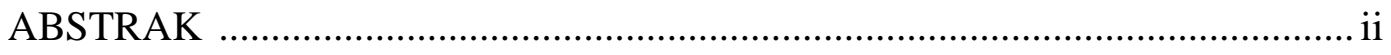

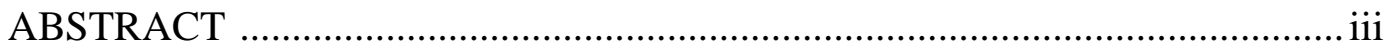

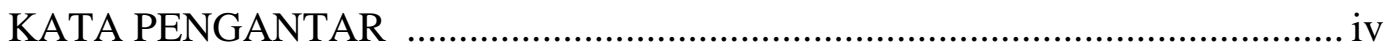

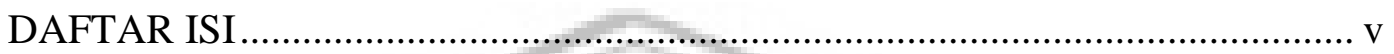

DAFTAR GAMBAR ........................................................................ viii

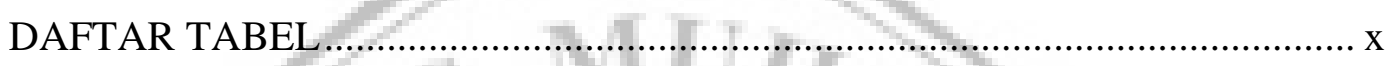

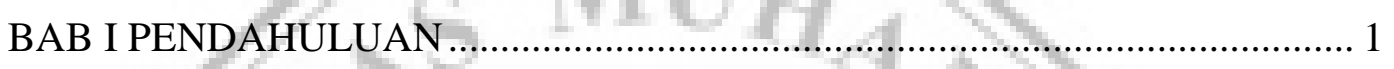

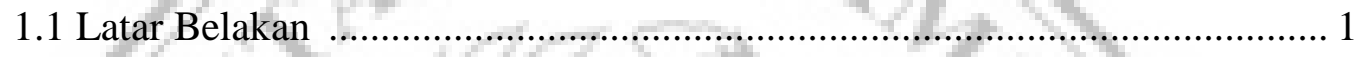

1.2 Rumusan Masalah …................................................................... 2

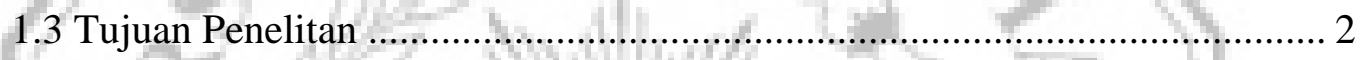

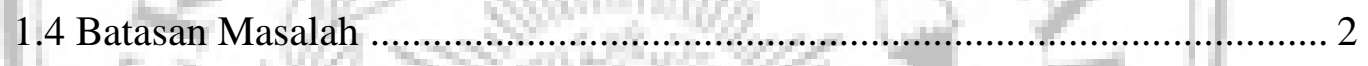

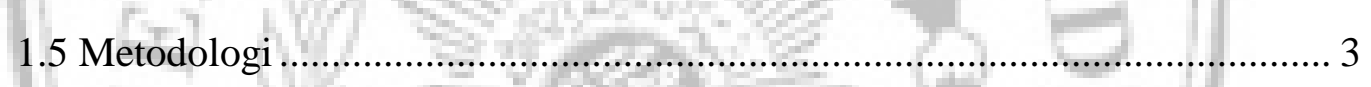

1.5.1 Studi Literatur …........................................................................ 3

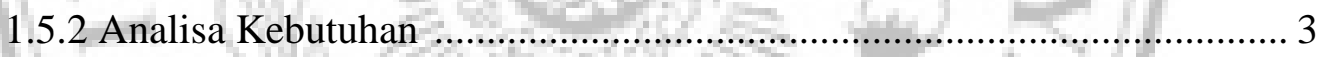

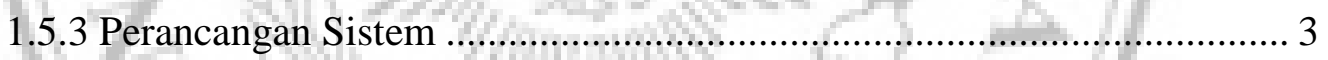

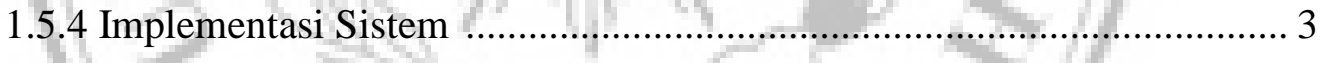

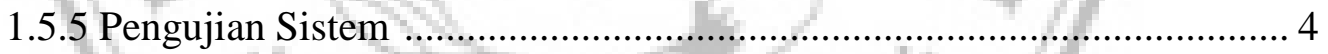

1.5.6 Penyusunan Laporan Tugas Akhir ...................................................... 4

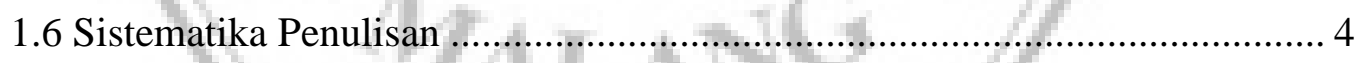

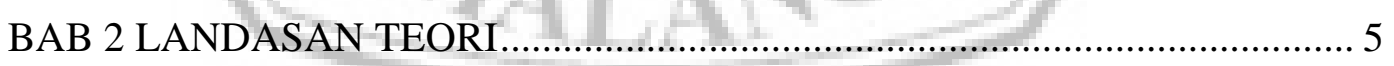

2.1 Penelitian Sebelumnya .......................................................................... 5

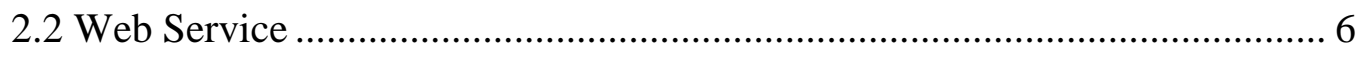

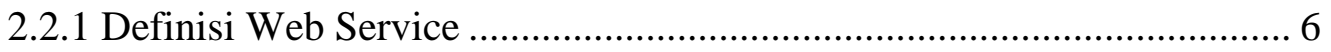

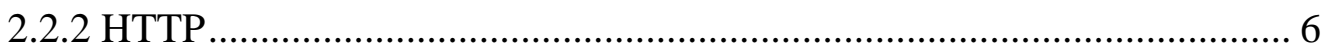

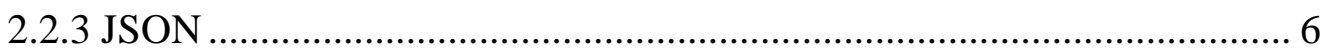

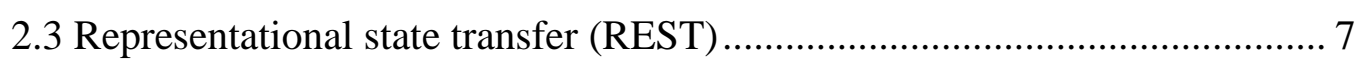

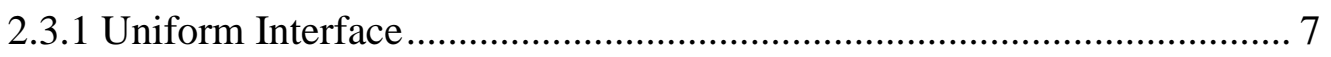

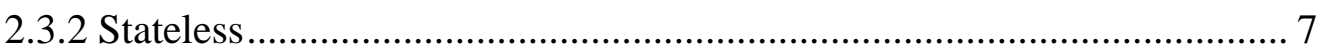


2.3.3 Layered System 8

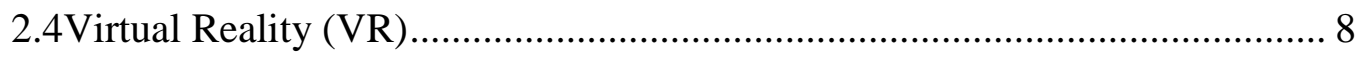

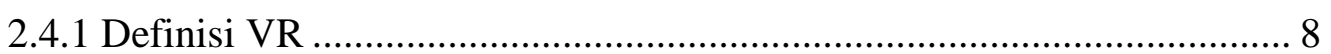

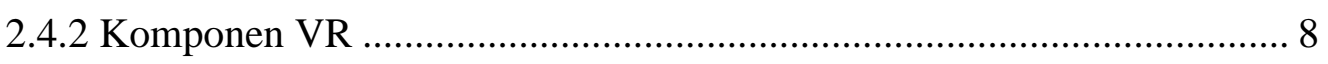

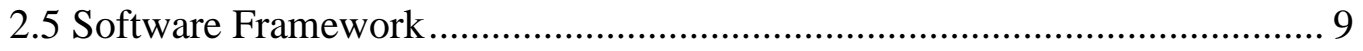

2.5.1 Definisi Software Framework ........................................................... 9

2.5.2 Keunggulan Menggunakan Framework ............................................. 10

2.5.3 Kekurangan Menggunakan Framework ........................................... 10

2.5.4. Model View Controller (MVC) …................................................. 10

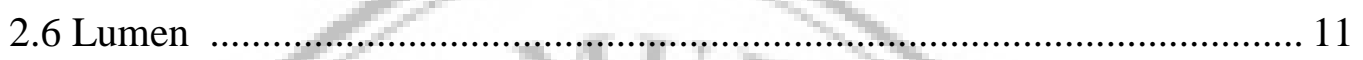

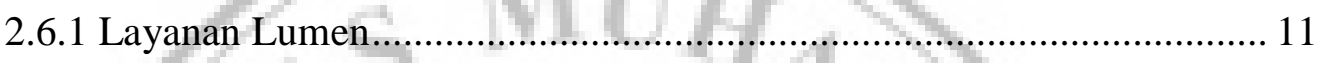

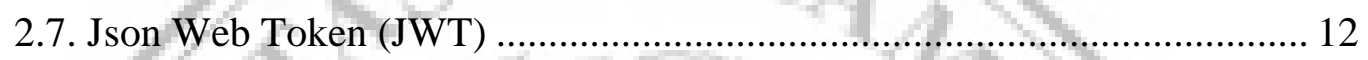

BAB III ANALISA DAN PERANCANGAN SISTEM .................................. 14

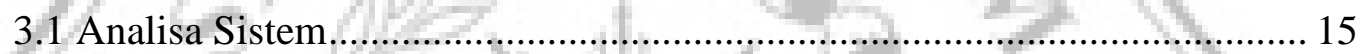

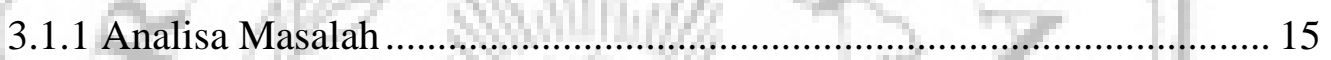

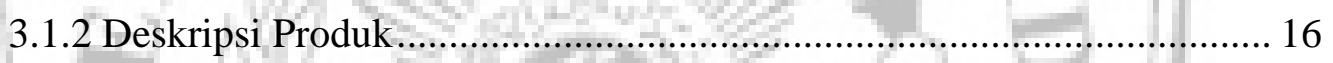

3.1.3 Analisa Kebutuhan fungsional ....................................................... 16

3.1.4 Analisa Kebutuhan Non Fungsional .................................................. 16

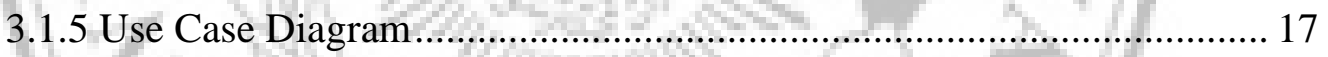

3.1.6 Definisi Use Case ...................................................................... 17

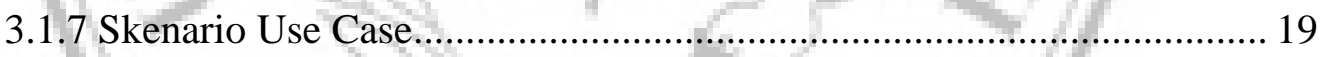

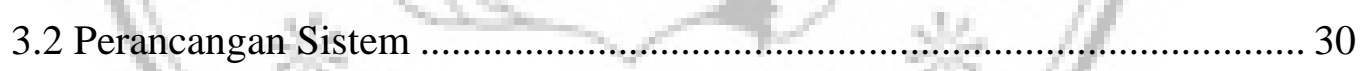

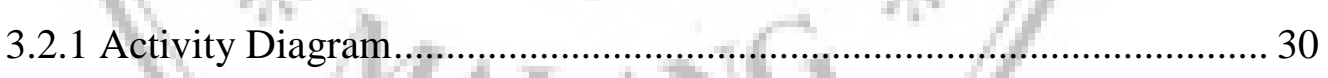

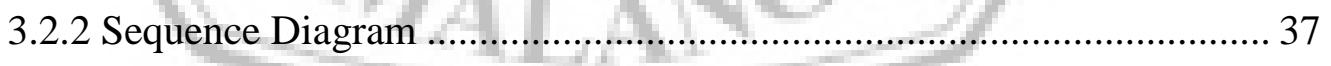

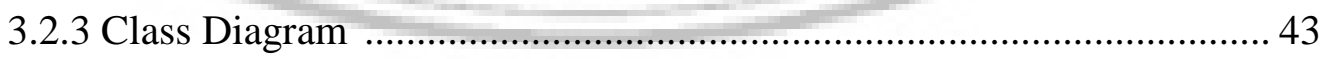

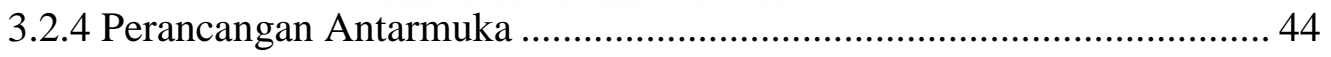

BAB IV IMPLEMENTASI DAN PENGUJIAN ................................................. 46

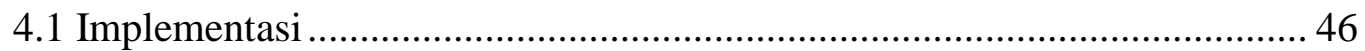

4.1.1 Lingkungan Pengembangan Perangkat Lunak ........................................ 46

4.1.2 Lingkungan Pengembangan Perangkat Keras........................................ 46

4.1.3 Implementasi Web Service berbasis RESTFUL .................................... 47

4.1.4 Implementasi Sistem Manajemen Virtual Shop..................................... 52 


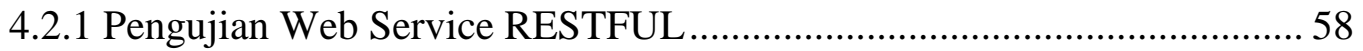

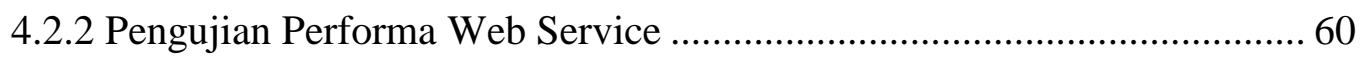

4.2.3 Pengujian Sistem Manajemen Virtual Shop ......................................... 62

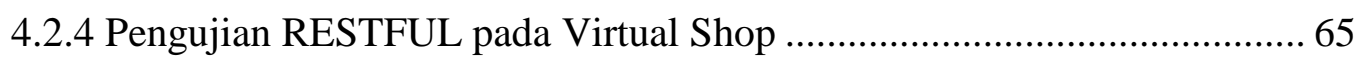

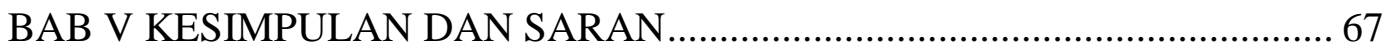

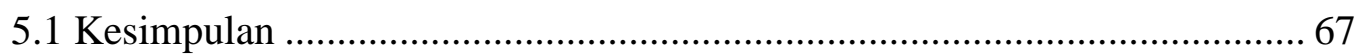

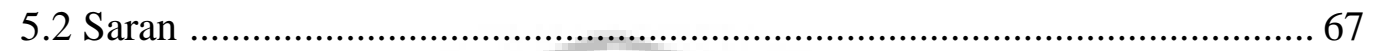

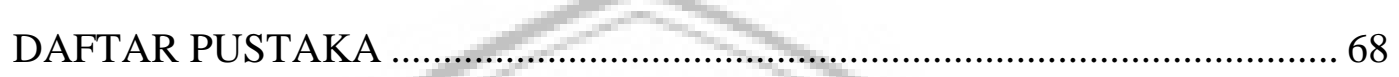

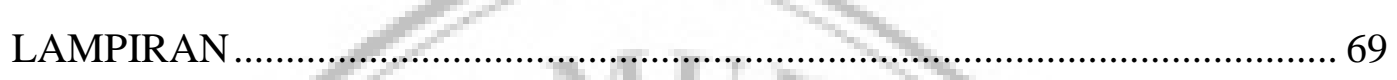

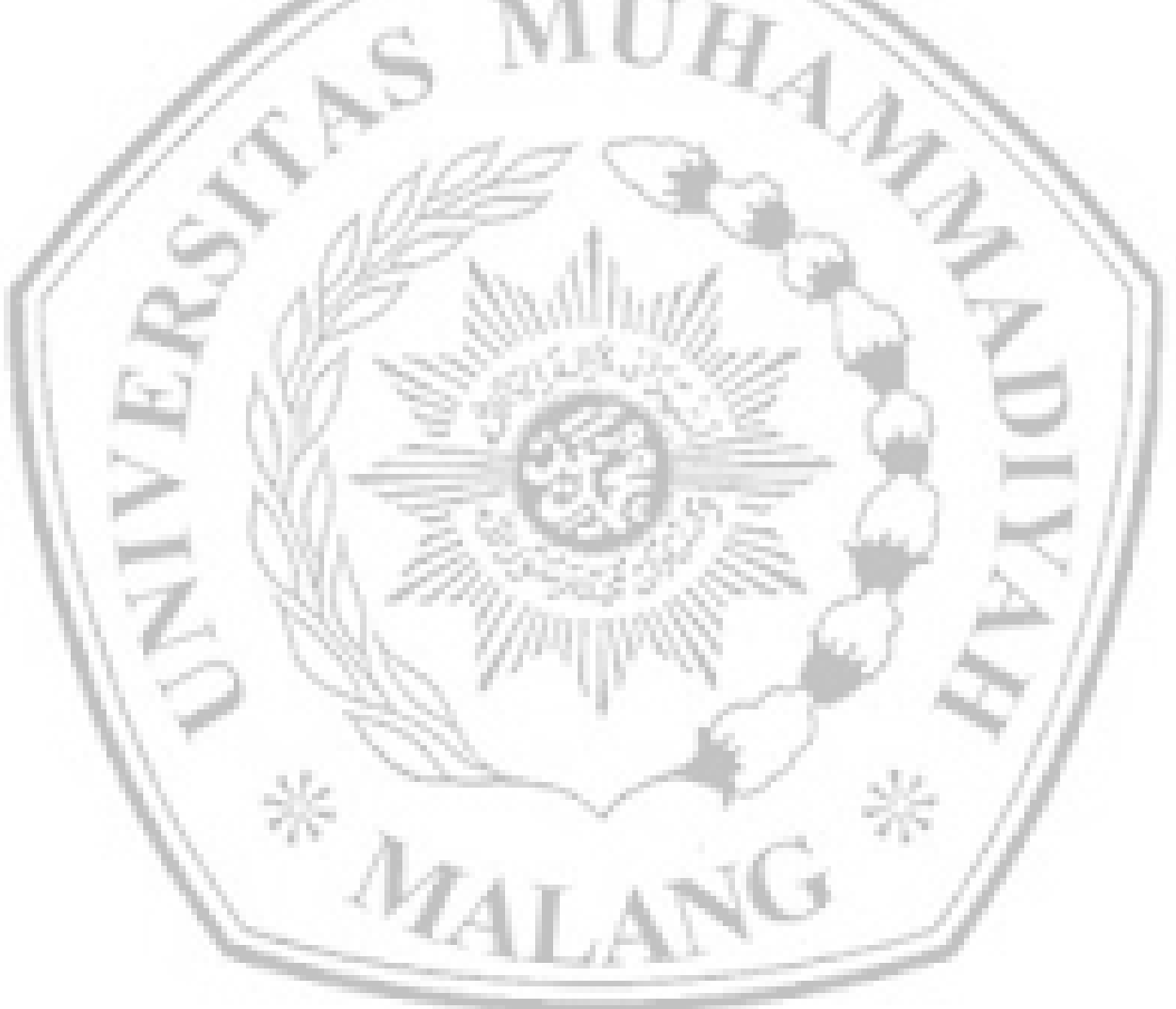




\section{DAFTAR GAMBAR}

Gambar 2.1 Contoh JSON .

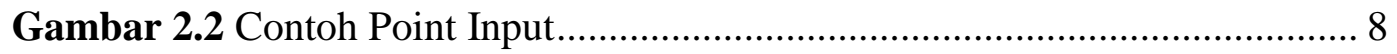

Gambar 2.3 Gambaran Umum MVC .............................................................. 11

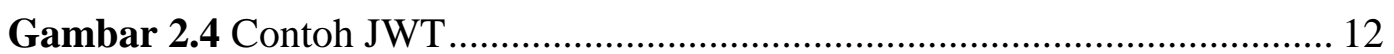

Gambar 3.1 Gambaran Umum Sistem Manajemen Virtual Shop ..................... 14

Gambar 3.2 Gambaran Umum RESTFUL pada Virtual Shop.......................... 14

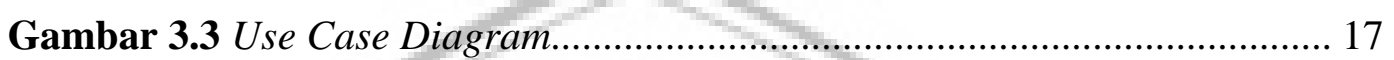

Gambar 3.4 Activity Diagram Pembelian ....................................................... 30

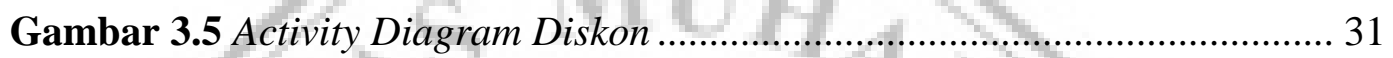

Gambar 3.6 Activity Diagram Pembayaran ................................................... 31

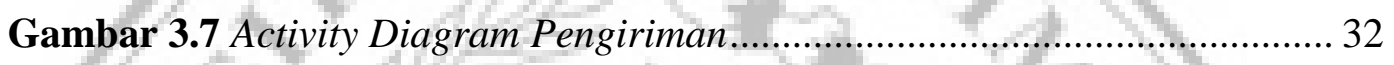

Gambar 3.8 Activity Diagram Validasi ....................................................... 32

Gambar 3.9 Activity Diagram Manajemen User ............................................ 33

Gambar 3.10 Activity Diagram Manajemen Lokasi ....................................... 33

Gambar 3.11 Activity Diagram Manajemen Region ........................................ 34

Gambar 3.12 Activity Diagram Manajemen Produk ........................................ 35

Gambar 3.13 Activity Diagram Manajemen Diskon Produk............................. 35

Gambar 3.14 Activity Diagram Manajemen Tata Letak ................................. 36

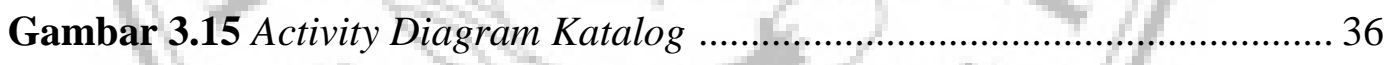

Gambar 3.16 Sequence Diagram Pembelian................................................... 37

Gambar 3.17 Sequence Diagram Diskon ..................................................... 38

Gambar 3.18 Sequence Diagram Pembayaran ................................................. 38

Gambar 3.19 Sequence Diagram Pengiriman................................................... 39

Gambar 3.20 Sequence Diagram Validasi ..................................................... 39

Gambar 3.21 Sequence Diagram Manajemen User ......................................... 40

Gambar 3.22 Sequence Diagram Manajemen Lokasi ..................................... 40

Gambar 3.23 Sequence Diagram Manajemen Region .................................... 41

Gambar 3.24 Sequence Diagram Manajemen Produk ..................................... 41

Gambar 3.25 Sequence Diagram Manajemen Diskon Produk.......................... 42

Gambar 3.26 Sequence Diagram Manajemen Tata Letak................................. 42 
Gambar 3.27 Sequence Diagram Katalog ..................................................... 43

Gambar 3.28 Class Diagram 1 ..................................................................... 43

Gambar 3.29 Class Diagram 2 ........................................................... 44

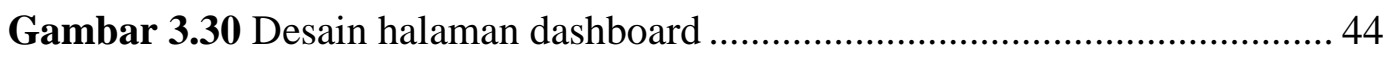

Gambar 3.31 Desain halaman manajemen ................................................ 45

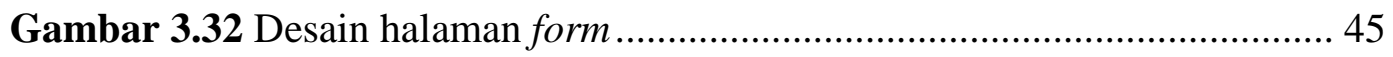

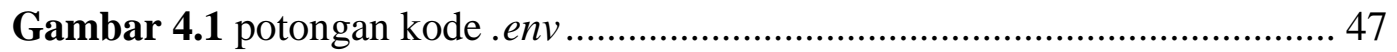

Gambar 4.2 potongan kode AuthServiceProvider.php ................................... 48

Gambar 4.3 potongan kode Authenticate.php ................................................. 48

Gambar 4.4 Halaman Login ....................................................................... 52

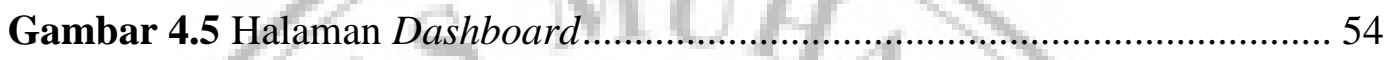

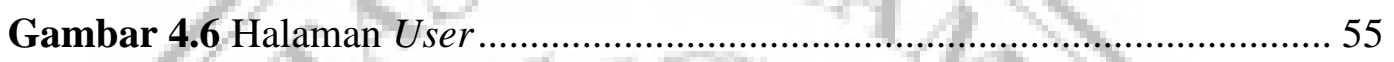

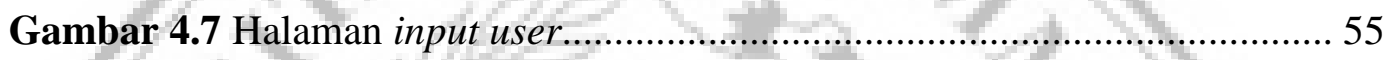

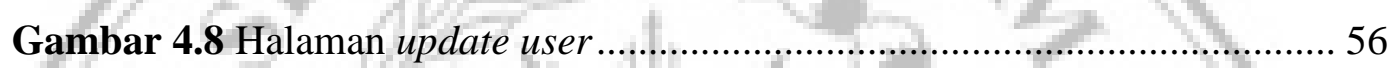

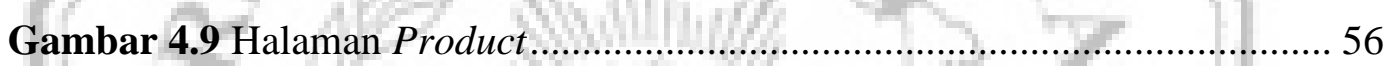

Gambar 4.10 Halaman Input Product .......................................................... 57

Gambar 4.11 Halaman Update Product ..................................................... 57

Gambar 4.12 Halaman Detail Order .......................................................... 58

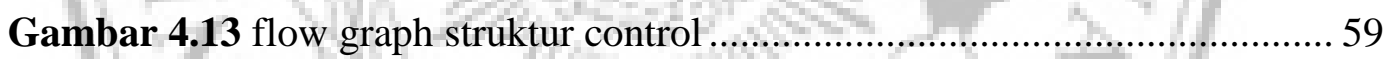

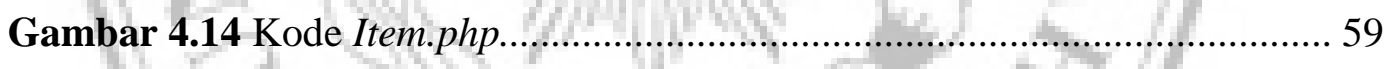

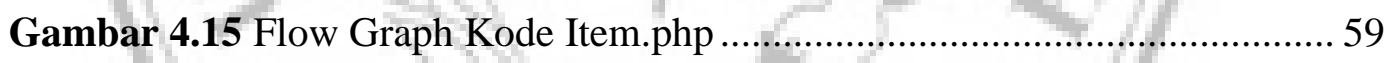




\section{DAFTAR TABEL}

Tabel 2.1 Perbedaan dengan Penelitian Sebelumnya .......................................... 5

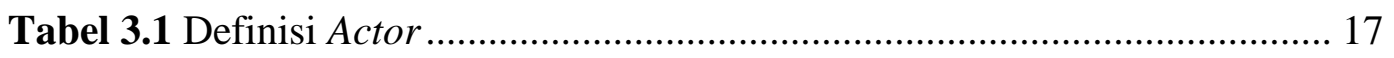

Tabel 3.2 Definisi Use Case ......................................................................... 18

Tabel 3.3 Skenario Use Case Pembelian 1....................................................... 19

Tabel 3.4 Skenario Use Case Pembelian 2........................................................ 19

Tabel 3.5 Skenario Use Case Diskon 1 ........................................................... 20

Tabel 3.6 Skenario Use Case Diskon 2 ............................................................. 20

Tabel 3.7 Skenario Use Case Pembayaran..................................................... 21

Tabel 3.8 Skenario Use Case Pengiriman 1 ................................................... 21

Tabel 3.9 Skenario Use Case Pengiriman 2 ................................................. 21

Tabel 3.10 Skenario Use Case Validasi ........................................................ 22

Tabel 3.11 Skenario Use Case Manajemen User 1 ........................................... 22

Tabel 3.12 Skenario Use Case Manajemen User 2 .......................................... 23

Tabel 3.13 Skenario Use Case Manajemen User 3 ........................................ 23

Tabel 3.14 Skenario Use Case Manajemen Lokasi 1........................................ 23

Tabel 3.15 Skenario Use Case Manajemen Lokasi 2 ........................................ 24

Tabel 3.16 Skenario Use Case Manajemen Lokasi 3 ....................................... 24

Tabel 3.17 Skenario Use Case Manajemen Region 1 ........................................ 25

Tabel 3.18 Skenario Use Case Manajemen Region 2 …................................... 25

Tabel 3.19 Skenario Use Case Manajemen Region 3 ........................................ 25

Tabel 3.20 Skenario Use Case Manajemen Produk 1 ........................................ 26

Tabel 3.21 Skenario Use Case Manajemen Produk 2 ....................................... 26

Tabel 3.22 Skenario Use Case Manajemen Produk 3 ......................................... 26

Tabel 3.23 Skenario Use Case Manajemen Diskon Produk 1 ............................. 27

Tabel 3.24 Skenario Use Case Manajemen Diskon Produk 2 ............................ 27

Tabel 3.25 Skenario Use Case Manajemen Diskon Produk 3 ............................ 28

Tabel 3.26 Skenario Use Case Manajemen Tata Letak 1 .................................... 28

Tabel 3.27 Skenario Use Case Manajemen Tata Letak 2 ................................. 29

Tabel 3.28 Skenario Use Case Manajemen Tata Letak 3 .................................. 29

Tabel 3.29 Skenario Use Case Katalog ............................................................ 29 
Tabel 4.1 Perangkat Keras Pembangun 47

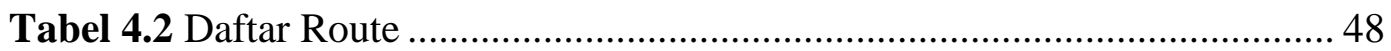

Tabel 4.3 Daftar Model …......................................................................... 49

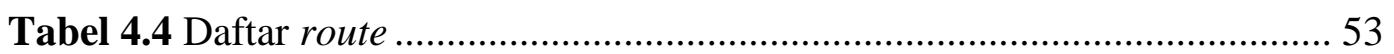

Tabel 4.5 Hasil Pengujian Web Service RESTFUL.......................................... 60

Tabel 4.6 Hasil Pengujian Performa Web Servis................................................ 61

Tabel 4.7 Hasil Pengujian Sistem Manajemen Virtual Shop ............................. 62

Tabel 4.8 Hasil pengujian RESTFUL pada Virtual Shop .................................. 65

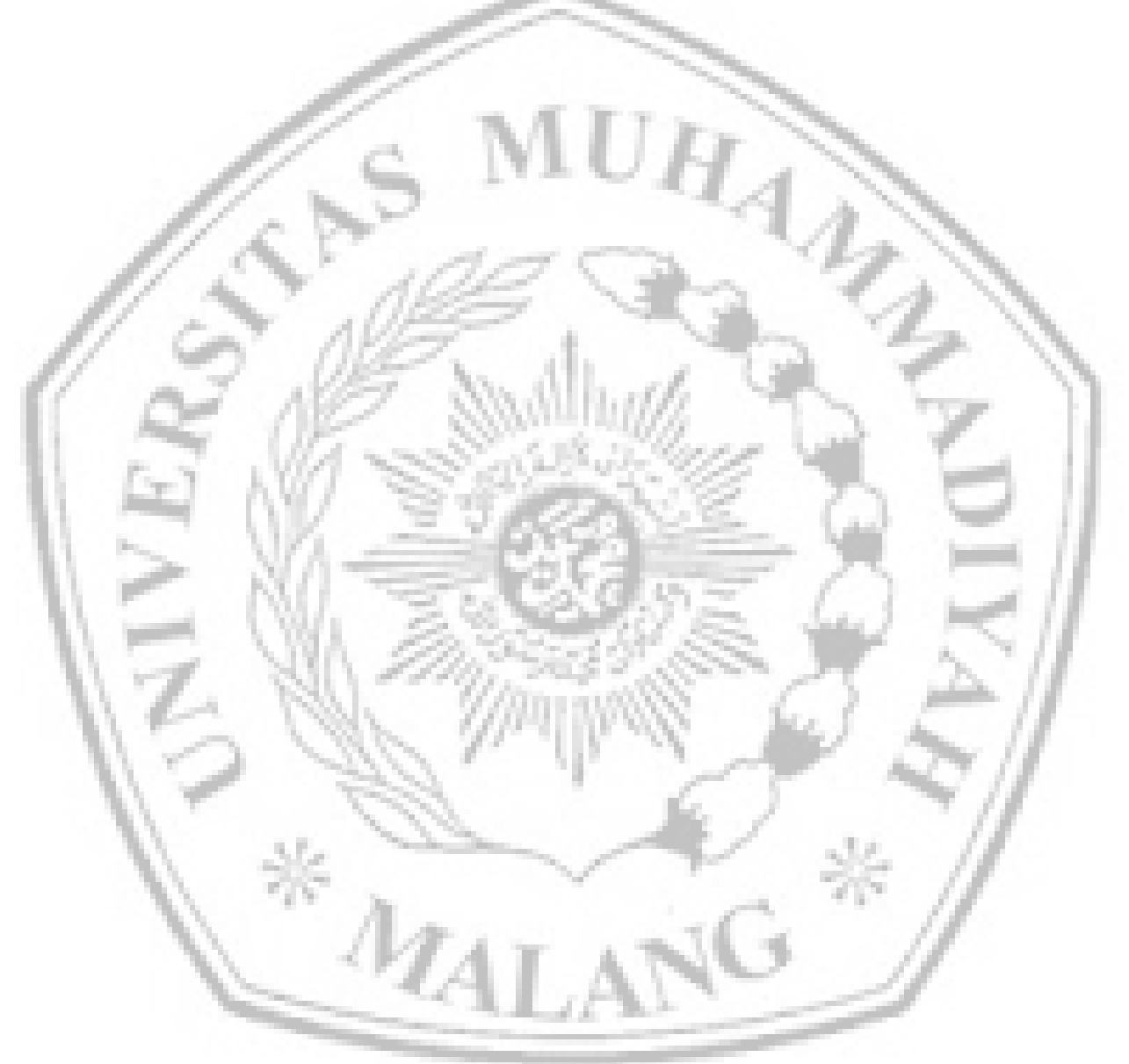




\section{DAFTAR PUSTAKA}

[1] R.Silva, J.C. Oliveira G.A.Giraldi, "Introduction to Virtual Reality," LNCC Research Report, Vol. 6, 2003.

[2] Cliona Ni Mhurcu and Ingrid Steenhuis Wilma Waterlander, "The Use of Virtual Reality in Study Complex Interventions, in Our Every-Day Food Environment," pp. 229-260, 2012.

[3] Roy Thomas Fielding, "Architectural Styles and the Design of Networkbased Software Architectures," 2000.

[4] Yudi Nugraha Bahar, "APLIKASI TEKNOLOGI VIRTUAL REALTY BAGI," 2014.

[5] Njeru Mwendi Edwin, "Software Frameworks, Architectural and Design Patterns," 2014.

[6] Zhiqiang Wei, Yongquan Yang Dandan Zhang, "Research on Lightweight MVC Framework Based on Spring MVC and Mybatis," 2013.

[7] K. Apu Iqbal H. Sarker, "MVC Architecture Design and Implementation of Java Framework for Developing Desktip Application," 2014.

[8] Eliyani Muhamad Haekal, "Token-based authentication using JSON Web Token on SIKASIR RESTful Web Service," 2016.

[9] Geoffrey K Gill, "Cyclometic Complexity Density and Software maintance productivity," 1997.

[10] Wilma E Waterlander, "The virtual supermarket: An innovative research," 2011.

[11] I Dewa Ayu Eka Yuliani, "PENERAPAN RAPID APPLICATION DEVELOPMENT PADA SISTEM PENJUALAN SEPEDA ONLINE," SIMETRIS, vol. 6, no. 1, pp. 27-36, April 2015.

[12] Joline Morrison, and Mike Morrison Nick Heidke, "Assessing the Effectiveness of the Model View Controller," 2009.

[13] Lin Huang, LiJing Liang, Jing Li Wei Cui, "The Research of PHP Development Framework Based on MVC Pattern," 2009.

[14] Patrick H. Smith, Ralph E. Johnson, and Munawar Hafiz Paul Adamczyk, "REST and Web Services In Theory," 2012.

[15] Xuan Shi, "The Semantics of Web Services An Examination in," 2013.

[16] Web Services Based On SOAP and REST Principles, "Web Services Based On SOAP and REST Principles," 2013.

[17] Sidhartha Reddy Vatrapu, "Design and Implementation of E-Commerce Site for Online Shopping," 2014.

[18] Erick Kurniawan, "IMPLEMENTASI REST WEB SERVICE UNTUK SALES ORDER," 2014. 